\title{
Chronic pancreatitis presenting as superior mesenteric artery syndrome
}

\author{
Sujit Kulkarni
}

Keck Medical Center of USC, Los Angeles, California, USA

\section{Correspondence to}

Dr Sujit Kulkarni,

sujit.kulkarni@med.usc.edu

Accepted 14 February 2015

\section{DESCRIPTION}

A 58-year-old woman was referred for surgical evaluation of chronic pancreatitis. Her pain started 6 months earlier along with anorexia and she lost 50 pounds. Two months earlier, she had started vomiting; the vomiting progressively got worse. She was vomiting three to four times a day after meals. She was able to eat only small portions of food and mostly preferred a liquid diet. She was also taking large quantities of narcotics for pain control. She had a history of alcoholism, diabetes and depression. She did not have any signs or symptoms of pancreatic exocrine insufficiency such as diarrhoea or steatorrhoea. She was seen by a local gastroenterologist and, based on her history, physical examination and imaging, she was diagnosed with chronic pancreatitis. Upper endoscopy demonstrated gastritis, oesophagitis and mild narrowing in the third portion of the duodenum. Pancreatic protocol CT scan demonstrated a dilated pancreatic duct with stones, dilated stomach and duodenum up to the level of the crossing of the superior mesenteric artery (SMA). There was no mass seen in the head of the pancreas. Tumour markers (carcinoembryonic antigen and cancer antigen 19-9) were within normal limits. Severe weight loss from chronic pancreatitis and anorexia caused loss of mesenteric fat around the SMA, which was causing duodenal obstruction (figure 1). The angle between aorta and SMA was $12^{\circ}$. The patient had chronic pancreatitis and partial duodenal obstruction due to SMA syndrome. Initially she was treated with conservative management. A percutaneous endoscopic gastrojejunostomy tube was placed for stomach decompression and enteral feeding. The patient was unable to tolerate enteral feeds even with pancreatic enzyme supplements. She was placed on total parenteral nutrition for 6 weeks but her symptoms persisted. The decision was made to bypass her duodenum as well as pancreatic duct surgically. She underwent loop duodenojejunostomy with mobilisation of ligament of
CrossMark

To cite: Kulkarni S. BMJ Case Rep Published online: [please include Day Month Year] doi:10.1136/bcr-2014207894

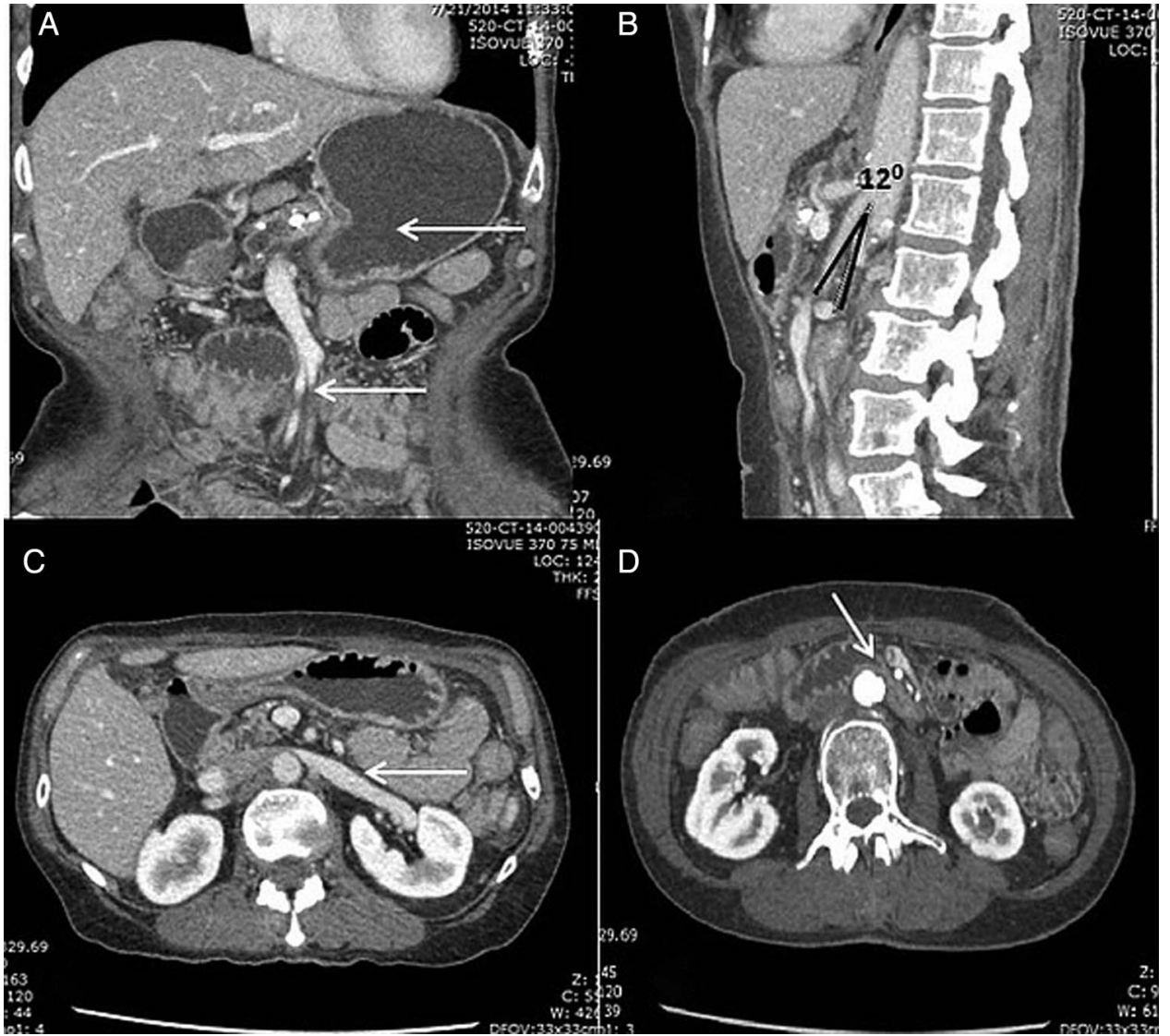

Figure 1 CT scan: (A) Dilated stomach and duodenum up to the crossing of superior mesenteric artery (SMA). (B) The angle between aorta and SMA is $12^{\circ}$. (C) Dilated left renal vein, which is compressed by SMA. (D) Compression of duodenum between aorta and SMA. 


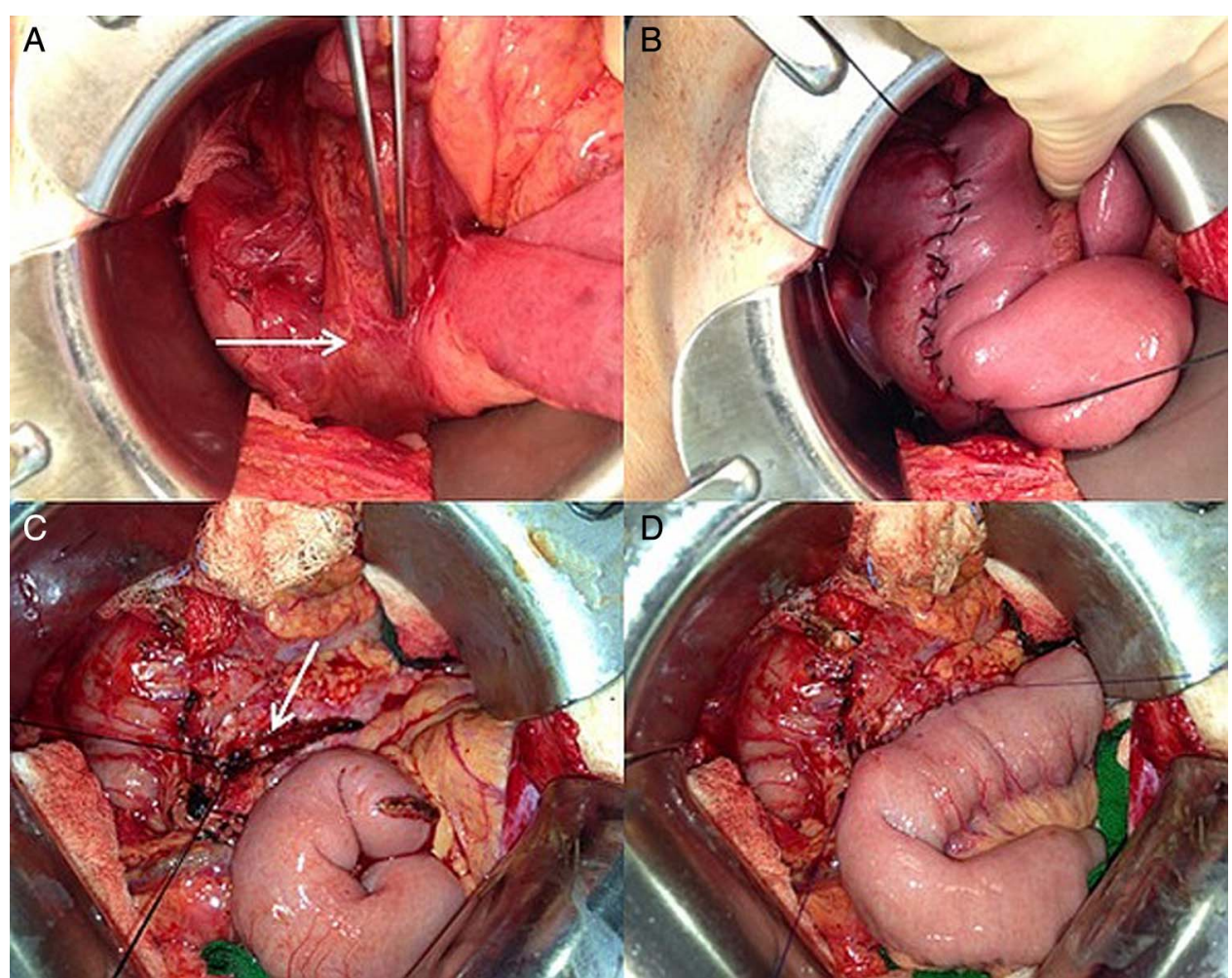

Figure 2 Intraoperative findings: (A) superior mesenteric artery crossing over duodenum. (B) Loop duodenojejunostomy anastomosis. (C) Pancreatic duct opened along its length with Roux-en-Y limb. (D) Lateral pancreaticojejunostomy.

Treitz. The pancreatic duct was opened along its length and stones were removed from the duct. A separate Roux-en-Y limb was created for lateral pancreaticojejunostomy. Side-to-side pancreaticojejunostomy was performed (figure 2: Puestow Procedure). The postoperative period was uneventful. The patient was able to tolerate a normal diet and has gained 15 pounds since the operation.

SMA syndrome is a rare condition and its diagnosis can be challenging. ${ }^{1}$ In patients presenting with nausea, vomiting, anorexia, severe weight loss, history of bariatric surgery, psychological disorders and spinal deformity, a diagnosis of SMA syndrome should be considered. ${ }^{2}$ Its association with psychological issues is well documented and the psychological well-being of these patients must be considered..$^{2}$ Medical management includes supportive care such as decompression and nutritional support. Surgical options include Strong's procedure (mobilisation of ligament of Treitz), duodenojejunostomy and gastrojejunostomy. Duodenojejunostomy has superior results compared to Strong's procedure and gastrojejunostomy. Surgical management has a higher rate of success and less chance of recurrence compared to medical management. ${ }^{3}$

\section{Learning points}

- Superior mesenteric artery syndrome is a rare condition. Diagnosis is often delayed and requires a high index of suspicion.

- It should be considered as a potential diagnosis in patients presenting with postprandial vomiting and severe weight loss.

- Open or laparoscopic duodenojejunostomy is preferred when medical management of the disease fails.

Competing interests None.

Patient consent Obtained.

Provenance and peer review Not commissioned; externally peer reviewed.

\section{REFERENCES}

1 Wilkie DP. Chronic duodenal ileus. Am J Med Sci 1927;173:643-9.

2 Merrett ND, Wilson RB, Cosman $P$, et al. Superior mesenteric artery syndrome: diagnosis and treatment strategies. J Gastroint Surg 2009;13:287-92.

3 Lee TH, Lee JS, Jo Y, et al. Superior mesenteric artery syndrome: where do we stand today? J Gastroint Surg 2012;16:2203-11. 
Copyright 2015 BMJ Publishing Group. All rights reserved. For permission to reuse any of this content visit http://group.bmj.com/group/rights-licensing/permissions.

BMJ Case Report Fellows may re-use this article for personal use and teaching without any further permission.

Become a Fellow of BMJ Case Reports today and you can:

- Submit as many cases as you like

- Enjoy fast sympathetic peer review and rapid publication of accepted articles

- Access all the published articles

- Re-use any of the published material for personal use and teaching without further permission

For information on Institutional Fellowships contact consortiasales@bmjgroup.com

Visit casereports.bmj.com for more articles like this and to become a Fellow 